\title{
DIVISÃO SOCIOESPACIAL DO TRABALHO E SEGMENTAÇÃO ESPACIAL DO MERCADO DE TRABALHO NO ESTADO DO RIO DE JANEIRO - 2000 A 2010
}

\author{
DIVISIÓN SOCIALESPACIAL DEL TRABAJO Y SEGMENTACIÓN \\ ESPACIAL DEL MERCADO LABORAL (DE TRABAJO) EN \\ EL ESTADO DEL RIO DE JANEIRO - 2000 A 2010
}

\section{SOCIOESPACIAL DIVISION OF LABOR AND SPACE SEGMENTATION OF THE LABOR MARKET IN THE STATE OF RIO DE JANEIRO - FROM 2000 TO 2010}
Marcelo Gomes Ribeiro - Universidade Federal do Rio de Janeiro - Rio de Janeiro - Rio de Janeiro - Brasil marceloribeiro@ippur.ufrj.br

Vitor Vilar Drumond - Universidade Federal do Rio de Janeiro - Rio de Janeiro - Rio de Janeiro - Brasil vitordrumond99@hotmail.com

\section{Resumo}

0 Estado do Rio de Janeiro (ERJ), após a crise na década de 1980, recebeu uma nova rodada de investimentos, principalmente no setor industrial. 0 aumento da exploração de petróleo na Bacia de Campos e a instalação da indústria automobilística no Vale do Paraíba indicam mudanças na estrutura espacial produtiva do ERJ, fato que gera influência direta na divisão socioespacial do trabalho e na segmentação espacial de seu mercado de trabalho. 0 presente trabalho buscou analisar se houve, de fato, um movimento de interiorização da economia e de seu mercado de trabalho. Para isso, utilizamos os dados do PIB municipal e do Censo Demográfico, ambos produzidos pelo IBGE, para 2000 e 2010. Como resultado, observamos perda de participação no Valor Adicionado Bruto industrial e de serviços da Região Metropolitana e consequente aumento nas mesorregiões Norte e Sul do Estado. 0 maior dinamismo econômico no Norte provocou o aumento do deslocamento casatrabalho de pessoas de outras regiões do Estado, porém isso não foi verificado na mesma intensidade no Sul, 0 que demonstra que as condições pretéritas da estrutura produtiva e do mercado de trabalho, associada ao tipo de investimento que cada mesorregião passou a ter, tiveram efeitos diferente entre essas regiões.

Palavras-chave: Divisão socioespacial do trabalho. Segmentação espacial do mercado de trabalho. Interiorização da economia.

\section{Abstract}

The Rio de Janeiro's State (ERJ), after the crisis in the 1980s, received a new round of investments, mainly in the industrial sector. The increase in oil exploration in the Bacia de Campos and the installation of the automobile industry in the Vale do Paraíba indicate changes in the productive spatial structure of the ERJ, a fact that generate direct influence in the sociospatial division of labor and in the spatial segmentation of the labor market. The current work tried to analyze if there was, in fact, a movement of interiorization of the economy. For this analysis, we will use the data of municipal GDP and the Demographic Census, both produced by IBGE, for 2000 and 2010. As a result, we observe a loss of participation in the Gross Value Added (GVA) of industry and services of the Metropolitan Region and consequent increase in the North and South mesoregions of the State. The greater economic dynamism in the northern led to an increase in the work-home movement of people from other regions of the State, but this was not verified in the same intensity in the South, which shows that the previous conditions of the productive structure and labor market, associated to the type of investment that each mesoregion had, had different effects between these regions.

Keywords: Socio-spatial division of labor. Spatial segmentation of the labor market. Internalization of the economy. 


\section{Resumen}

El Estado de Rio de Janeiro (ERJ), tras la crisis en la década de 1980, recibió una nueva ronda de inversiones, principalmente en el sector industrial. El aumento de la explotación de petróleo en la Bacia de Campos y la instalación de la industria automovilística en el Vale do Paraíba indican cambios en la estructura espacial productiva del ERJ, hecho que generaría influencia directa en la división socioespacial del trabajo y en la segmentación espacial de su mercado de mercado laboral. El presente trabajo buscó analizar si hubo, de hecho, un movimiento de interiorización de la economía. Para ese análisis, utilizaremos los datos del PIB municipal y del Censo Demográfico, ambos producidos por el IBGE, para 2000 y 2010. Como resultado, observamos pérdida de participación en el Valor Añadido Bruto (VAB) industrial y de servicios de la Región Metropolitana y consecuente aumento en las mesorregiones Norte y Sur del Estado. El mayor dinamismo económico en el Norte provocó el aumento del desplazamiento casa-trabajo de personas de otras regiones del Estado, pero eso no fue verificado en la misma intensidad en el Sur, lo que demuestra que las condiciones pretéritas de la estructura productiva y del mercado de trabajo, asociada al tipo de inversión que cada mesorregión pasó a tener, tuvieron efectos diferentes entre esas regiones.

Palabras clave: División socioespacial del trabajo. Segmentación espacial del mercado laboral. Interiorización de la economía.

\section{Introdução}

Após a crise na década de 1980 (Baltar, 1996), o Estado do Rio de Janeiro (ERJ) recebeu uma nova rodada de investimentos tanto na década que se seguia, quanto na década de 2000 (Hasenclever, 2012). A conjuntura dos anos 2000 trazia a esperança e a certeza, depois confirmada, para um novo ciclo de desenvolvimento no país, de investimentos públicos e privados em infraestrutura e produção, colocados como pauta prioritária do governo. A inserção de uma agenda desenvolvimentista ressuscitou no Rio de Janeiro a possibilidade de retomada de sua primazia no cenário nacional enquanto participação na economia. Conforme Silva (2012), mesmo recebendo investimentos a partir da década de 1930, o ERJ já vinha passando por contínuas perdas de participação em relação à economia nacional em todos os três setores de atividade econômica. Essas perdas se evidenciaram com a clara dificuldade enfrentada pelo ERJ em se desenvolver no mesmo ritmo expansivo que os outros estados, a exemplo de São Paulo, que se consolidava frente à economia nacional. Esta competitividade com as demais unidades da federação, segundo Siqueira (2015), colocou o ERJ em posição secundária na economia nacional. Os crescentes avanços tecnológicos desenvolvidos pelos demais estados confrontaram-se com o ritmo de crescimento das atividades do Rio de Janeiro que, antes pioneiras, agora se tornavam obsoletas. Ao mesmo tempo, a transferência da capital federal para Brasília fez com que o estado perdesse o posto de centro administrativo e, consequentemente, de grande parte dos investimentos públicos. 
No Rio de Janeiro, a partir dos anos 90, grande parte dos investimentos ocorreu no setor industrial, com destaque para a indústria extrativa mineral. O aumento da exploração de petróleo na Bacia de Campos (Siqueira, 2015), a instalação da indústria automobilística no Vale do Paraíba (Silva, 2012; Arbix; Rodríguez-Pose, 1999) e diversos outros investimentos realizados durante o período indicam mudanças na estrutura produtiva do ERJ, fato que, caso confirmado, geraria influência direta na divisão socioespacial do trabalho e, também, na segmentação espacial de seu mercado de trabalho.

Historicamente percebe-se a Região Metropolitana do Rio de Janeiro (RMRJ) como a localidade com maior número de postos de trabalho dentro do ERJ, fato estritamente ligado à sua diversidade na estrutura produtiva. Como destaca Oliveira (2017), espaços dotados de mercados diversificados tendem a oferecer mais oportunidades quando comparados a economias especializadas. Se, por um lado, investimentos ocorridos fora da RMRJ abrem margem para uma nova divisão socioespacial do trabalho; por outro, há de se recordar que não se deixou de investir na metrópole. Inclusive, o próprio Complexo Petroquímico do Rio de Janeiro (COMPERJ) exemplifica isso. O COMPERJ teria como insumo a produção da indústria extrativa alvo de massivos investimentos - localizada no Norte, mas o encadeamento necessário para agregação de valor se daria na RMRJ, mais especificamente em Itaboraí. Ainda, como mostram Osório, Rego e Versiani (2016), essa poderia ser uma grande oportunidade para o adensamento produtivo no território, visto que a grande maioria das atividades produtivas necessárias ao atendimento das demandas da extração de petróleo em alto mar encontra-se fora do estado do Rio de Janeiro.

Em relação ao mercado de trabalho do Norte Fluminense, apesar da intensificação da exploração do petróleo na Bacia de Campos, rica em petróleo, a custa dos investimentos ocorridos no início de 2000, as características intrínsecas a ela podem apresentar entraves para uma nova segmentação espacial do mercado de trabalho. Primeiro, o mercado de trabalho da indústria extrativa necessita de um alto grau de especialização, no qual não se encontra mão de obra qualificada abundante, muito menos na região em que se localiza. Segundo, quando se fala em mercados de trabalho na indústria extrativa é importante abordá-la stricto sensu, ou seja, como um nicho pequeno marcado pela sazonalidade que se dá na jornada de trabalho e no pouco vínculo da mão de obra com a localidade. Em decorrência disso, o alto grau de especialização gera uma demanda 
de mão de obra que não será satisfeita na sua própria região, isto atrai outros trabalhadores provenientes de outras regiões e, somando-se a alta remuneração, gera um cenário que dificulta a integração dos indivíduos com a localidade, visto que parte deles voltam para suas residências localizadas em outra mesorregião - durante seu período de descanso.

Mas o debate regional não se limita à dicotomia RMRJ-Norte, há um destaque pela conjuntura que se deu em benefício da região Norte, porém houve outras mesorregiões que receberam investimentos. O Vale do Paraíba, aqui inserido na mesorregião Sul, como dizem Osório, Rego e Versiani (2016), teve investimentos a partir da instalação de plantas vinculadas à indústria automobilística (montagem de automóveis e caminhões e produção de autopeças) em meados da década de 90, o que, em conjunto com a expansão da economia, poderia gerar bons frutos para a região. Ainda em relação ao Sul, também é preciso destrinchar seus municípios para que se possam compreender na totalidade as mudanças ocorridas e para que não haja uma ideia de unidade nessa região. Diferente do Norte, a estrutura produtiva Sul Fluminense apresenta um processo de formação industrial recente e, ao mesmo tempo, um processo já consolidado. Quanto ao processo já consolidado entende-se como a instalação da maior indústria siderúrgica da América Latina, a Companhia Siderúrgica Nacional (CSN), criada nos anos 40, e também da Usina de Angra dos Reis, instalada entre as décadas de 1970 e 1980.

Esses fatos referentes à rodada de investimentos que o ERJ teve merecem um estudo aprofundado, buscando analisar se houve, de fato, um movimento de interiorização da economia, seguido de uma nova divisão socioespacial do trabalho e, por conseguinte, mudanças na segmentação espacial do mercado de trabalho. Fazer o diagnóstico comparativo de 2000 e 2010 nos possibilita ver se a conjuntura apresentada já emitiu resultados de mudanças na divisão socioespacial do trabalho e, por conseguinte, na segmentação espacial do mercado de trabalho, ou se há indicativos contrários. Assim, a nossa hipótese é que, nesse período, houve mudanças na divisão socioespacial do trabalho com reflexos em alterações na segmentação espacial do mercado de trabalho, apesar de não serem mudanças tão substantivas e em todas as direções.

Para discussão da hipótese apresentada, organizamos este trabalho em mais três seções, além desta introdução. Na segunda seção, será feita análise da divisão socioespacial do trabalho segundo as mesorregiões 
do ERJ, a partir dos dados agregados do PIB municipal, na perspectiva de verificar se houve alteração na estrutura econômica desses espaços de análise. Na terceira seção, será feita análise comparativa do mercado de trabalho dos principais recortes espaciais discutidos neste trabalho (RMRJ, Norte e Sul), a partir dos dados Censo Demográfico do IBGE, pois são os únicos que permitem análise do mercado de trabalho com a abrangência espacial nesse nível territorial. E, como dito, será feita por meio da análise da estrutura sócio-ocupacional de cada espaço e do deslocamento casa-trabalho entre regiões. Por fim, na última seção, são feitas as considerações finais na perspectiva de sumarizar os principais resultados encontrados.

\section{Divisão socioespacial do trabalho no Estado do Rio de Janeiro}

Esta seção abordará a divisão socioespacial do trabalho no ERJ, entendida como a estrutura econômica de cada mesorregião do Estado, a partir da utilização dos dados do Produto Interno Bruto (PIB) Municipal para os anos de 2000-2010. A hipótese que norteou o trabalho nesta seção é que a rodada de investimentos não foi capaz de provocar mudanças substantivas na divisão socioespacial do trabalho nesse período, por mais que os indicadores econômicos apontem para um crescimento da indústria no estado e maior participação de mesorregiões não metropolitanas.

Nos dados referentes à participação dos setores de atividade econômica no PIB de cada região e do ERJ (Tabela 1), foi possível identificar, preliminarmente, que a composição da estrutura produtiva das mesorregiões não é semelhante tanto entre elas quanto se comparado ao Estado, à exceção da Região Metropolitana ${ }^{1}$, que é a que mais apresenta semelhança.

A participação do setor industrial no PIB do ERJ, além de relevante, aumentou no período de 2000 a 2010 , passando de $20,4 \%$ para $23,7 \%$. Porém, é possível observar a heterogeneidade da participação desse setor de atividade econômica nas regiões do estado. Enquanto na Região Metropolitana, Noroeste e Centro há participações que variam entre 14,9\% e 20,0\%, no Norte, Sul e Baixadas as participações variam entre 34,0\% e $60,8 \%$. Em geral, houve mais mesorregiões ganhando participação deste setor em seu PIB, no período analisado, fato que influencia o aumento verificado no estado. 
A pauta dos investimentos apresentada provoca um olhar mais sensível para o Norte e o Sul do estado. A indústria na primeira mesorregião mantém a mesma participação apresentada, enquanto no Sul há perda. Os dados indicam certa contradição nos reflexos produzidos, visto que os investimentos, embora realizados na indústria, não somente não surtiram efeitos em ganhos de participação como houve um benefício do setor de serviços em ambos os casos.

Tabela 1 - Participação dos setores no PIB das Mesorregiões e do Estado do Rio de Janeiro

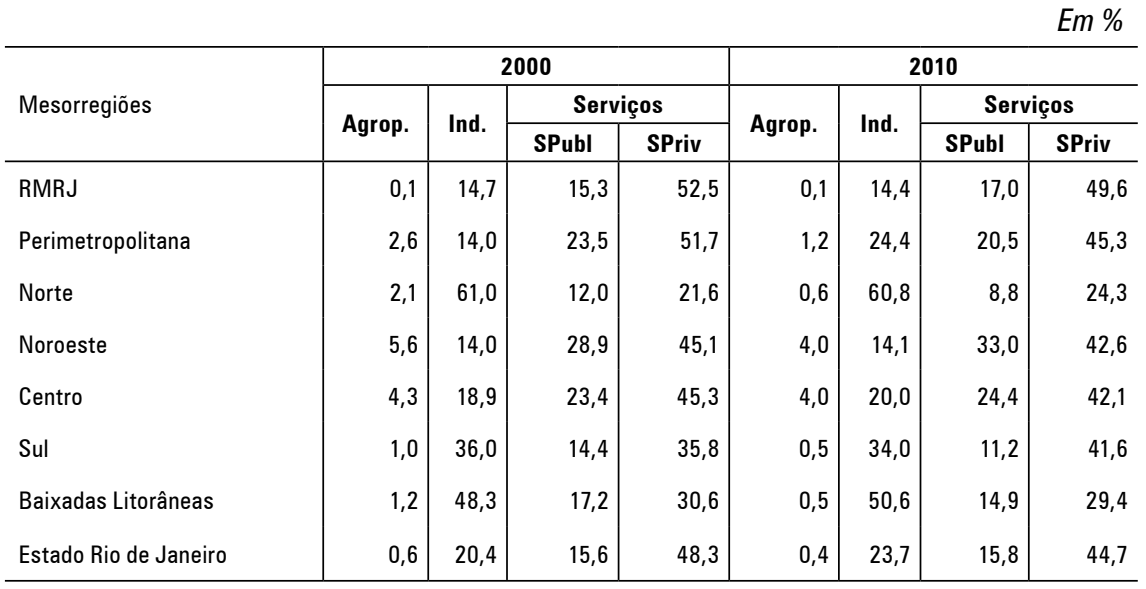

Fonte: IBGE - Censo Demográfico. Elaboração própria, 2017.

Ao expandir a análise para a participação no PIB estadual, tem-se uma visão clara da dinâmica regional presente no ERJ (Tabela 2). O PIB da Região Metropolitana, embora com perda entre 2000 e 2010, representa no último ano $71,2 \%$ do ERJ, fato que evidencia a importância das decisões tomadas em esfera estadual para essa região, assim como, nas decisões dos municípios presentes na mesma. Ainda, não pode ser ignorado o papel do Rio de Janeiro na participação acima destacada, pois somente a capital representava, em 2010, 46,7\% do PIB fluminense, fator que a confirma como cidade polarizadora da região. A segunda mesorregião com maior participação, o Norte, representa 11,2\% do PIB estadual em 2010, quando em 2000 era de apenas 6,5\%. Porém, ao analisar a distribuição interna, é possível ver a importância dos municípios de Campos dos Goytacazes e Macaé, que juntos somavam 9\% do PIB estadual, em 2010. Já no Sul, há uma distribuição de participação mais homogênea entre 
os municípios, mas ainda assim enxerga-se Volta Redonda e Angra dos Reis, juntos, representando quase metade do PIB de sua mesorregião. De todo modo, a região Sul também aumentou sua participação entre 2000 e 2010, passando de 7,5\% para 9,8\%, respectivamente. A RMRJ, o Norte e o Sul são as regiões com as maiores participações no PIB do Estado, o que justifica uma análise mais centrada nessas regiões.

Apesar de continuar havendo concentração econômica na RMRJ em 2010, houve perda de participação da metrópole no VAB industrial do estado e de modo menos pronunciado no VAB de serviços no período analisado. Em relação ao VAB industrial, houve perda de participação da RMRJ no estado de 55,3\% para $41,3 \%$. Por outro lado, as regiões Norte e Sul que em 2000 apresentavam juntas uma participação no VAB industrial do estado de 32,7\% passaram a apresentar, em 2010, 42,7\%, o que corresponde a uma participação superior a da RMRJ. A indústria extrativa no Norte fluminense e a instalação da indústria automobilística no Sul fluminense foram fatores importantes para isto. Fatores que também podem ter refletido no setor de serviços, pois se verifica um aumento das duas mesorregiões, o que pode estar ligado à logística necessária para a existência das indústrias.

Tabela 2 - Participação das mesorregiões no Valor Adicionado Bruto (VAB) setorial e no PIB do Estado do Rio de Janeiro

$E m \%$

\begin{tabular}{l|r|r|r|r|r|r|r|r}
\hline \multirow{2}{*}{ Mesorregiões } & \multicolumn{4}{|c|}{2000} & \multicolumn{4}{|c}{2010} \\
\cline { 2 - 9 } & $\begin{array}{r}\text { VAB } \\
\text { Agro }\end{array}$ & \multicolumn{1}{|c|}{$\begin{array}{c}\text { VAB } \\
\text { Indústria }\end{array}$} & $\begin{array}{c}\text { VAB } \\
\text { Serviços }\end{array}$ & $\begin{array}{c}\text { PIB } \\
\text { ERJ }\end{array}$ & $\begin{array}{c}\text { VAB } \\
\text { Agro }\end{array}$ & $\begin{array}{c}\text { VAB } \\
\text { Indústria }\end{array}$ & $\begin{array}{c}\text { VAB } \\
\text { Serviços }\end{array}$ & $\begin{array}{c}\text { PIB } \\
\text { ERJ }\end{array}$ \\
\hline RMRJ & 13,1 & 55,3 & 81,2 & 76,6 & 16,2 & 41,3 & 74,8 & 67,9 \\
Perimetropolitana & 14,3 & 2,1 & 3,6 & 3,0 & 11,5 & 3,4 & 3,6 & 3,3 \\
Norte & 24,7 & 19,4 & 3,4 & 6,5 & 20,2 & 28,6 & 6,1 & 11,2 \\
Noroeste & 11,1 & 0,8 & 1,3 & 1,1 & 10,7 & 0,6 & 1,2 & 1,0 \\
Centro & 16,7 & 2,0 & 2,3 & 2,2 & 22,1 & 1,7 & 2,2 & 2,0 \\
Sul & 13,3 & 13,3 & 5,9 & 7,5 & 12,4 & 14,1 & 8,6 & 9,8 \\
Baixadas Litorâneas & 6,7 & 7,2 & 2,3 & 3,1 & 7,0 & 10,3 & 3,6 & 4,9 \\
Total & 100 & 100 & 100 & 100 & 100 & 100 & 100 & 100 \\
\hline
\end{tabular}

Fonte: IBGE - PIB Municipal. Elaboração, 2017. 
Podemos, portanto, concluir que, apesar de a Região Metropolitana do Rio de Janeiro continuar mantendo maior concentração econômica no ERJ, houve redução de sua participação e consequente aumento da participação das mesorregiões Norte e Sul, tanto no referente ao PIB, quanto no referente ao VAB industrial. Isso demonstra que nos anos 2000 ocorreu relativa mudança na divisão socioespacial do trabalho no Estado do Rio de Janeiro. A questão, a saber, é se essa mudança provocou também alterações na segmentação espacial no mercado de trabalho entre as regiões do ERJ. É o que tentaremos discutir na próxima seção, focando a análise na RMRJ, no Norte Fluminense e no Sul Fluminense, por serem as regiões que apresentaram maior destaque econômico no período (ver mapa abaixo).

Figura 1- Estado do Rio de Janeiro: mesorregiões geográficas Norte e Sul e região metropolitana do Rio de Janeiro, 2018

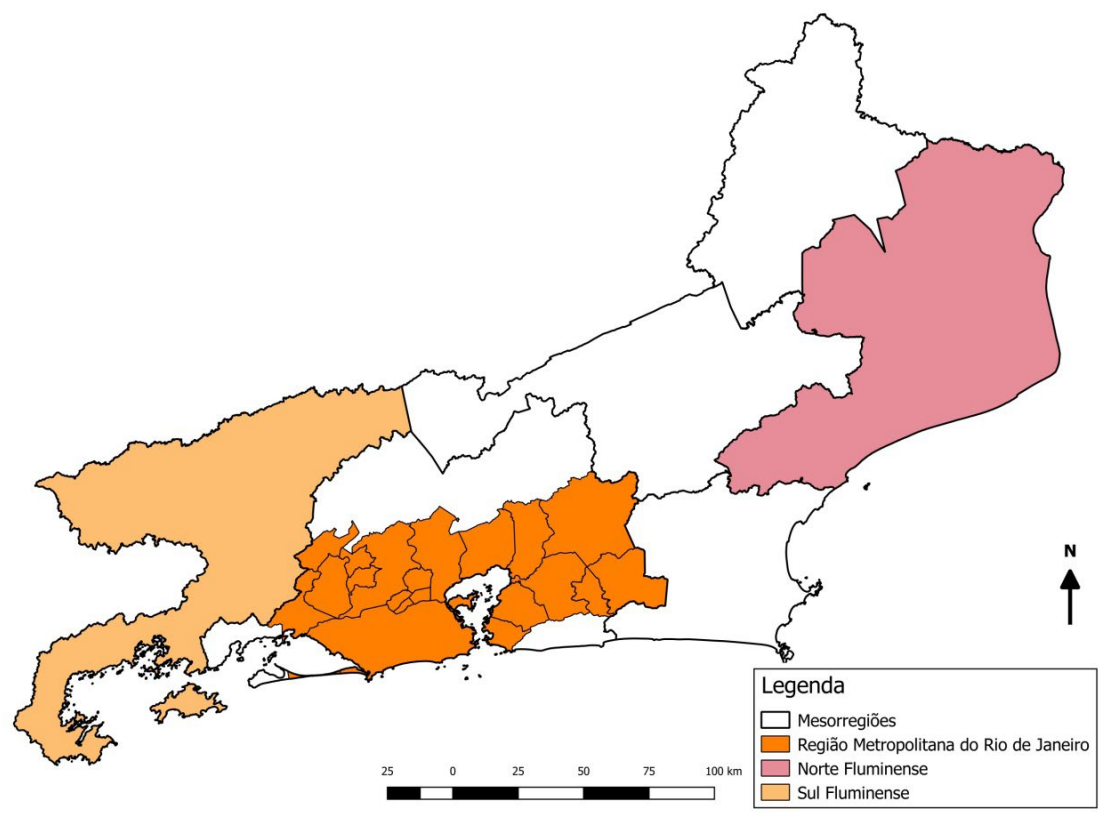

Fonte: IBGE, 2018. 


\section{Segmentação espacial do mercado de trabalho}

Após levantarmos a discussão da divisão socioespacial do trabalho nos anos 2000, tendo em vista a conjuntura econômica desse período, vamos analisar nesta seção a segmentação espacial do mercado de trabalho. Nossa hipótese, que busca ser confirmada e toma força com base na seção anterior, é que os investimentos que têm provocado relativa alteração na divisão socioespacial do trabalho, principalmente no que refere ao setor industrial, não foram capazes de alterar a segmentação espacial do mercado de trabalho, devido, principalmente, aos deslocamentos casatrabalho de trabalhadores residentes em regiões diferentes daquelas em que passaram a exercem sua ocupação no mercado de trabalho.

Para a análise será utilizado o esquema de estratificação social elaborado pelo Observatório das Metrópoles, devido à sua capacidade de expressar a estrutura social do território regional fluminense e as possíveis mudanças ocorridas. Como descrevem Ribeiro, Ribeiro e Costa (2013, p. 30),

O esquema de estratificação social do Observatório das Metrópoles foi construído por meio da categoria ocupação, respeitando os princípios da oposição capital e trabalho, oposição entre posição de comando e de subordinação, trabalho não-manual e trabalho manual, considerando trabalho público e privado, os setores de atividade econômica e tendo como filtro para algumas categorias a escolaridade e a renda. Com base nesses princípios, foram agrupadas as ocupações, de forma hierárquica, em 24 categorias sócio-ocupacionais.

Na Tabela 3 estão apresentadas as 24 categorias sócio-ocupacionais, agrupadas nas oito grupos sócio-ocupacionais ${ }^{2}$, segundo os dados dos Censos Demográficos de 2000 e 2010.

A categoria dos dirigentes sofreu perda relativa em todas as regiões, fato que pode ser explicado pelo aumento da ocupação no estado, tendo em vista que o acesso ao emprego se dá em categorias mais baixas, características opostas aos dirigentes.

Os profissionais do nível superior apresentam uma variação positiva em todas as mesorregiões do estado, episódio que retratou uma tendência geral da especialização do mercado de trabalho brasileiro na primeira década do século XXI, decorrente, principalmente, dos empregados de nível superior e dos estatutários de nível superior que compóem esse grupo, 
embora num patamar inferior houve também aumento das categorias de autônomos de nível superior e de professores de nível superior.

Dentro das ocupações médias, a tendência geral foi de perda de participação em todas as mesorregiões do ERJ, exceto no Norte Fluminense. Nessa mesorregião houve um aumento nas categorias das ocupações técnicas e ocupações de escritório, categorias que podem estar relacionadas pela presença de atividade industrial no território: as ocupações técnicas, muitas delas ligadas diretamente às atividades industriais, e as ocupações de escritório por se ligarem de modo indireto, tendo em vista que o investimento no setor industrial provoca encadeamento em outros ramos de atividade econômica, como no setor de serviços.

Tabela 3 - Categorias sócio-ocupacionais do da Região Metropolitana do Rio de Janeiro, da mesorregião Norte Fluminense, da mesorregião Sul Fluminense e do Estado do Rio de Janeiro - 2000 e 2010

(Em \%)

\begin{tabular}{|c|c|c|c|c|c|c|c|c|}
\hline \multirow{2}{*}{ CATEGORIAS SÓCIO-OCUPACIONAIS } & \multicolumn{2}{|c|}{ RMRJ } & \multicolumn{2}{|c|}{ Norte } & \multicolumn{2}{|c|}{ Sul } & \multicolumn{2}{|c|}{ ERJ } \\
\hline & 2000 & 2010 & 2000 & 2010 & 2000 & 2010 & 2000 & 2010 \\
\hline DIRIGENTES & 2,1 & 1,5 & 1,1 & 0,9 & 1,6 & 1,2 & 2,0 & 1,4 \\
\hline Grandes Empregadores & 1,1 & 0,8 & 0,7 & 0,6 & 1,0 & 0,8 & 1,1 & 0,8 \\
\hline Dirigentes do Setor Público & 0,3 & 0,3 & 0,2 & 0,3 & 0,3 & 0,3 & 0,3 & 0,3 \\
\hline Dirigentes do Setor Privado & 0,7 & 0,3 & 0,2 & 0,1 & 0,3 & 0,1 & 0,6 & 0,3 \\
\hline PROFISSIONAIS DE NÍVEL SUPERIOR & 8,5 & 12,3 & 4,6 & 8,6 & 5,7 & 8,6 & 7,9 & 11,7 \\
\hline Profissionais Autônomos de Nível Superior & 2,0 & 2,4 & 0,9 & 1,4 & 1,3 & 1,6 & 1,9 & 2,3 \\
\hline Profissionais Empregados de Nível Superior & 3,6 & 5,7 & 1,7 & 3,4 & 2,1 & 3,7 & 3,3 & 5,3 \\
\hline Profissionais Estatutários de Nível Superior & 0,9 & 1,3 & 0,3 & 0,6 & 0,4 & 0,5 & 0,8 & 1,2 \\
\hline Professores de Nível Superior & 2,0 & 2,9 & 1,7 & 3,2 & 1,9 & 2,7 & 1,9 & 2,9 \\
\hline PEQUENOS EMPREGADORES & 2,0 & 1,2 & 1,7 & 0,9 & 2,0 & 1,3 & 2,0 & 1,2 \\
\hline Pequenos Empregadores & 2,0 & 1,2 & 1,7 & 0,9 & 2,0 & 1,3 & 2,0 & 1,2 \\
\hline OCUPAÇÕES MÉDIAS & 27,9 & 26,7 & 21,3 & 23,3 & 22,1 & 21,3 & 26,8 & 25,9 \\
\hline Ocupações Artísticas e Similares & 1,4 & 1,4 & 1,1 & 1,1 & 0,9 & 1,0 & 1,3 & 1,4 \\
\hline Ocupações de Escritório & 9,6 & 9,9 & 6,8 & 8,0 & 7,3 & 7,0 & 9,1 & 9,5 \\
\hline Ocupações de Supervisão & 3,9 & 4,3 & 2,5 & 3,1 & 3,6 & 3,8 & 3,8 & 4,2 \\
\hline Ocupações Técnicas & 5,7 & 4,6 & 3,7 & 4,9 & 4,4 & 4,3 & 5,4 & 4,6 \\
\hline Ocupações Médias da Saúde e Educação & 4,3 & 4,2 & 5,3 & 5,2 & 4,2 & 4,0 & 4,3 & 4,2 \\
\hline Ocupações de Segurança Pública, Justiça e Correios & 3,0 & 2,2 & 2,0 & 1,1 & 1,6 & 1,1 & 2,8 & 2,1 \\
\hline
\end{tabular}


(Em \%)

\begin{tabular}{|c|c|c|c|c|c|c|c|c|}
\hline \multirow{2}{*}{ CATEGORIAS SÓCIO-OCUPACIONAIS } & \multicolumn{2}{|c|}{ RMRJ } & \multicolumn{2}{|r|}{ Norte } & \multicolumn{2}{|r|}{ Sul } & \multicolumn{2}{|r|}{ ERS } \\
\hline & 2000 & 2010 & 2000 & 2010 & 2000 & 2010 & 2000 & 2010 \\
\hline $\begin{array}{l}\text { TRABALHADORES DO TERCIÁRIO } \\
\text { ESPECIALIZADO }\end{array}$ & 20,4 & 20,2 & 18,3 & 18,0 & 19,9 & 19,3 & 20,2 & 19,8 \\
\hline Trabalhadores do Comércio & 9,4 & 11,1 & 9,4 & 10,1 & 10,0 & 10,7 & 9,4 & 10,9 \\
\hline Prestadores de Serviços Especializados & 11,1 & 9,1 & 8,9 & 7,9 & 9,9 & 8,6 & 10,8 & 8,9 \\
\hline TRABALHADORES DO SECUNDÁRIO & 20,2 & 20,2 & 23,7 & 25,5 & 26,1 & 28,3 & 20,9 & 21,2 \\
\hline Trabalhadores da Indústria Moderna & 3,9 & 3,7 & 4,5 & 5,1 & 6,9 & 8,1 & 4,0 & 3,9 \\
\hline Trabalhadores da Indústria Tradicional & 3,9 & 2,9 & 4,7 & 3,3 & 3,0 & 2,7 & 4,0 & 3,1 \\
\hline Operários dos Serviços Auxiliares & 5,1 & 5,4 & 4,6 & 5,8 & 5,7 & 7,1 & 5,0 & 5,4 \\
\hline Operários da Construção Civil & 7,3 & 8,3 & 9,8 & 11,3 & 10,5 & 10,4 & 7,8 & 8,8 \\
\hline $\begin{array}{l}\text { TRABALHADORES DO TERCIÁRIO NÃO } \\
\text { ESPECIALIZADO }\end{array}$ & 18,4 & 17,3 & 18,8 & 15,9 & 19,1 & 16,6 & 18,6 & 17,3 \\
\hline Prestadores de Serviços Não Especializados & 5,3 & 6,2 & 6,0 & 6,0 & 5,6 & 5,9 & 5,4 & 6,1 \\
\hline Trabalhadores Domésticos & 8,8 & 9,3 & 9,3 & 7,9 & 10,4 & 9,3 & 9,2 & 9,3 \\
\hline Ambulantes e Biscateiros & 4,3 & 1,8 & 3,5 & 1,9 & 3,0 & 1,5 & 4,1 & 1,8 \\
\hline TRABALHADORES AGRÍCOLAS & 0,6 & 0,7 & 10,3 & 6,9 & 3,6 & 3,4 & 1,6 & 1,5 \\
\hline Agricultores & 0,6 & 0,7 & 10,3 & 6,9 & 3,6 & 3,4 & 1,6 & 1,5 \\
\hline Total & 100 & 100 & 100 & 100 & 100 & 100 & 100 & 100 \\
\hline
\end{tabular}

Fonte: IBGE, Censo Demográfico 2000 e 2010. Elaboração própria a partir das categorias sócio-ocupacionais do Observatório das Metrópoles, 2017.

Nos trabalhadores do secundário, observa-se que houve aumento de participação nas regiões Norte e Sul, ao contrário do que ocorreu na RMRJ que manteve sua participação. $\mathrm{O}$ aumento naquelas regiões se deu principalmente devido ao aumento dos trabalhadores da indústria moderna e dos operários dos serviços auxiliares. Isso pode ser justificado pelo tipo de investimento industrial ocorrido nessas regiões, a indústria automobilística e a indústria extrativa, no Sul e no Norte, respectivamente, capazes de potencializar os serviços ligados à logística industrial. A RMRJ e o Norte tiveram também aumento da participação dos operários da construção civil, comportamento verificado, de modo geral, em todo o país, mas a região Sul praticamente manteve sua participação nessa categoria sócio-ocupacional. 
Em relação aos trabalhadores do serviço não especializado, é possível confirmar o resultado da conjuntura nacional do período analisado quando se observa que houve redução na participação dos ambulantes e biscateiros em todas as mesorregiões, devido à expansão do emprego, principalmente formal, no Brasil. Essa categoria tem uma característica importante, pois ela é marcada justamente pela informalidade, ou seja, sofreu positivamente o impacto do aumento das ocupações e da formalização do trabalho. Porém, a categoria dos trabalhadores domésticos só sofreu aumento na RMRJ, tendo em vista que nas regiões Norte e Sul houve redução de sua participação no período. Os prestadores de serviços não especializados também sofreram aumento na RMRJ e ainda na região Sul, porém, manteve a mesma participação na região Norte no período analisado.

Portanto, quando se faz a análise comparativa das regiões no período 2000-2010, o que se vê é mudanças pontuais da estrutura sócioocupacional em todas as regiões. A RMRJ alterou, sobretudo a participação dos profissionais de nível superior e dos trabalhadores do terciário não especializado, tendo em vista aumento da primeira e redução da participação da segunda categoria sócio-ocupacional. O Norte e o Sul Fluminenses registraram aumento nas categorias dos profissionais de nível superior e dos trabalhadores do secundário, mas reduziu a participação dos trabalhadores do terciário não especializado. Ou seja, a grande diferença entre essas últimas regiões e a RMRJ é que naquelas houve aumento de participação dos trabalhadores do secundário, o que não ocorreu na RMRJ. E esse aumento decorreu principalmente de maior participação dos trabalhadores da indústria moderna e dos operários dos serviços auxiliares. Isso significa que os investimentos industriais realizados nos anos 2000 contribuíram para aumento das ocupações ligadas ao setor secundário. A questão é saber se esse aumento se deu pela incorporação da mão de obra existente na própria região (tanto no Norte quanto no Sul) ou se foi necessário atrair mão de obra de outras regiões, o que será feito a seguir a partir dos dados de deslocamento inter-regional.

\section{Região Norte Fluminense}

Quando se considera a região de origem das pessoas que se deslocam para a mesorregião Norte, podemos observar que houve aumento da atração exercida por essa mesorregião de todos os tipos de 
origem (Baixada Litorânea, RMRJ, outros municípios), entre 2000 e 2010, conforme apresentado na Tabela 5. Porém, como em 2000 não é possível diferenciar o motivo do deslocamento (se é para trabalho ou para estudo), fica difícil saber se esse aumento decorreu predominantemente por motivo de trabalho. De todo modo, como o aumento do deslocamento, em termos absolutos, foi muito elevado, considerando todas as origens, observa-se que em 2010 o motivo trabalho apresentou maior participação dentre os tipos de deslocamento, o que possibilita constatar que a mesorregião Norte passou a atrair mais mão de obra ao longo do período analisado.

Na Tabela 4 também podemos observar que, em 2010, o maior deslocamento das pessoas para a mesorregião Norte era da mesorregião das Baixadas Litorâneas (excluíndo os deslocamentos internos da própria mesorregião), fato que expõe uma dinâmica existente entre as duas mesorregiões, tendo em vista que em 2000 esse deslocamento era 2.455 pessoas e em 2010 passou para 21.651 pessoas, o que significa um aumento de $782 \%$ no período. Isso demonstra que muitos municípios das Baixadas Litorâneas são impactados pela atividade da indústria extrativa no Norte, sendo que esses impactos são vistos desde a esfera econômica - com uma geração de atividades ligadas à indústria - até a esfera social, como aqui tratamos do mercado de trabalho. Houve aumento dos deslocamentos casa-trabalho da Região Metropolitana do Rio de Janeiro para a mesorregião Norte, haja vista que em 2000 o deslocamento nesse sentido era feito por 6.633 pessoas e em 2010 passou a ser feito por 11.673 pessoas, representando um aumento de $76 \%$. Também houve aumento de deslocamento de outros municípios do Estado do Rio de Janeiro e do Brasil para a mesorregião Norte, passando de 7.406 pessoas, em 2000, para 21.058 pessoas, em 2010, o que corresponde a 184\%. A atração, portanto, de pessoas de outras regiões para a mesorregião Norte aumentou de 16.494 pessoas para 54.382 pessoas, entre 2000 e 2010, ou seja, trata-se de um aumento de $230 \%$. Como esse aumento foi expressivo, a questão que se coloca é se ele foi capaz de alterar a estrutura sócio-ocupacional da mesorregião Norte. É o que veremos a seguir. 
Tabela 4 - Município de origem das pessoas que realizam deslocamento para mesorregião Norte Fluminense para trabalho ou estudo - 2000 e 2010

\begin{tabular}{|c|c|c|c|c|c|c|c|c|}
\hline \multirow{5}{*}{ Município de origem } & \multicolumn{8}{|c|}{ Deslocamento para mesorregião Norte } \\
\hline & \multirow{3}{*}{\multicolumn{2}{|c|}{2000}} & \multicolumn{6}{|c|}{2010} \\
\hline & & & \multicolumn{4}{|c|}{ Motivo } & \multirow{2}{*}{\multicolumn{2}{|c|}{ Total }} \\
\hline & & & \multicolumn{2}{|c|}{ Trabalho } & \multicolumn{2}{|c|}{ Estudo } & & \\
\hline & N. & $\%$ & N. & $\%$ & N. & $\%$ & N. & $\%$ \\
\hline Municípios da mesorregião Norte & 10.263 & 38,4 & 20.657 & 31,4 & 6.188 & 40,2 & 26.876 & 33,1 \\
\hline Mun. Mesorregião das Baixadas Litorâneas & 2.455 & 9,2 & 18.350 & 27,9 & 3.273 & 21,3 & 21.651 & 26,6 \\
\hline Municípios da RMRJ & 6.633 & 24,8 & 9.596 & 14,6 & 2.062 & 13,4 & 11.673 & 14,4 \\
\hline Outros municípios do ERJ e Brasil & 7.406 & 27,7 & 17.168 & 26,1 & 3.864 & 25,1 & 21.058 & 25,9 \\
\hline Total & 26.757 & 100 & 65.771 & 100 & 15.387 & 100 & 81.258 & 100 \\
\hline
\end{tabular}

Fonte: IBGE, Censo Demográfico 2000 e 2010. Elaboração própria, 2017.

Os dados da Tabela 5 nos mostra a participação da população ocupada da mesorregião Norte das categorias sócio-ocupacionais segundo os ocupados residentes na referida mesorregião e os ocupados que se deslocam para ela. De início, nota-se um aumento de participação dos ocupados que se deslocam para o Norte em todas as categorias, exceto duas (ocupações artísticas e similares e trabalhadores domésticos). Porém, os principais destaques são das categorias dos dirigentes do setor privado (aumento de 14 pontos percentuais - pp), profissionais empregados de nível superior (10,2 pp), das ocupações técnicas (16,7 pp) e dos trabalhadores da indústria tradicional (11,6 pp) que tiveram aumento de mais de dois dígitos (em pontos percentuais) na participação dos ocupados que se deslocam para a mesorregião Norte. Num segundo plano, com aumento entre 5 e 10 pontos percentuais na participação dos deslocamentos de cada categoria, também se destacam os operários dos serviços auxiliares $(8,5)$, ocupações de supervisão $(7,7)$, trabalhadores da indústria moderna $(6,5)$, estatutários de nível superior $(6,3)$, ocupações de escritório $(6,3)$, dirigentes do setor público $(5,4)$ e os professores de nível $(5,1)$. Isso demonstra que os principais aumentos ocorreram em categorias ligadas ao setor público ou às atividades produtivas propriamente ditas. 
Tabela 5 - Participação dos ocupados residentes na mesorregião Norte Fluminense e dos ocupados que se deslocam para mesorregião Norte Fluminense para trabalho por categoria sócio-ocupacional - 2000 e 2010

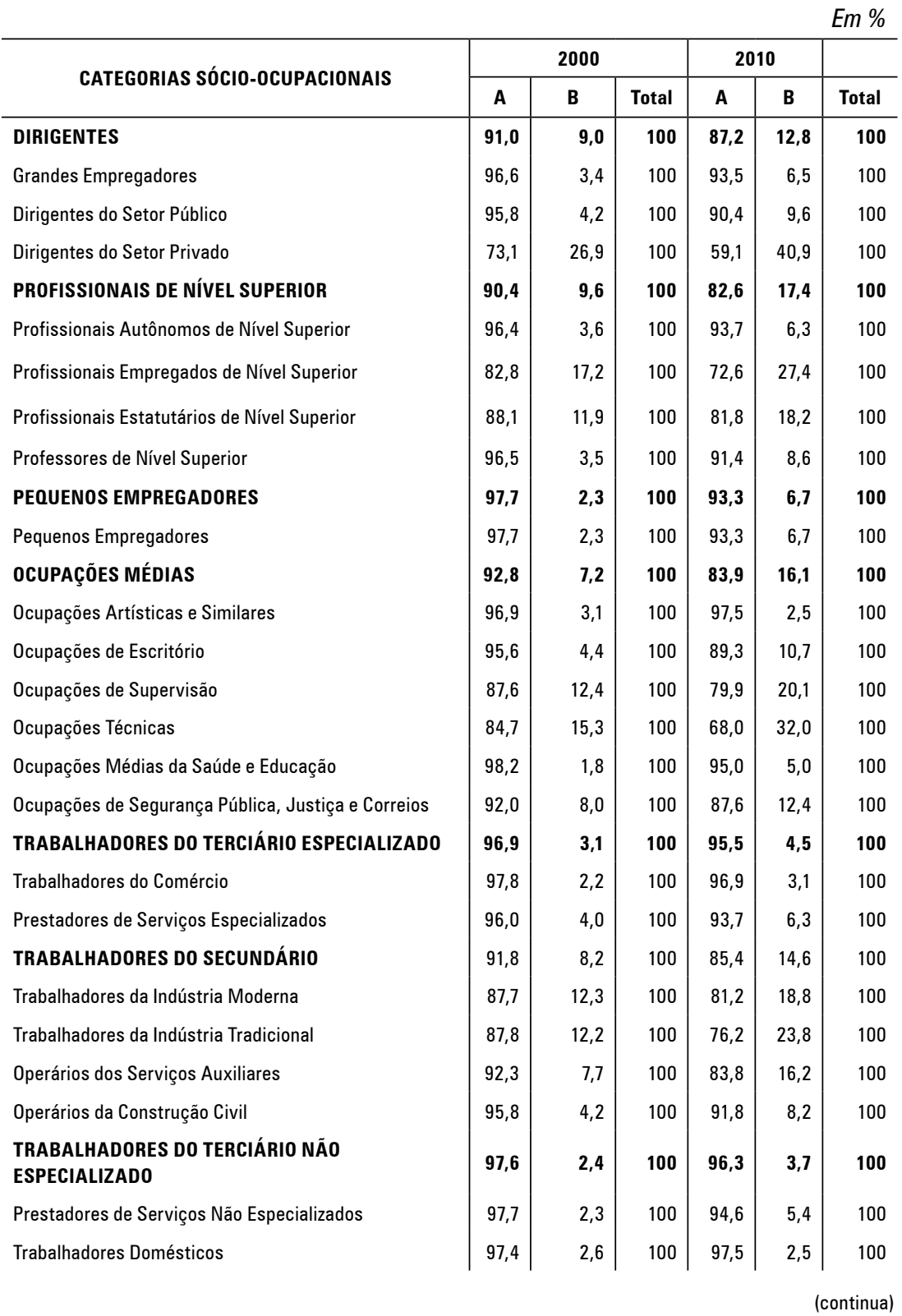


Em \%

\begin{tabular}{l|r|r|r|r|r|r}
\hline \multirow{2}{*}{ CATEGORIAS SÓcIO-OCUPACIONAIS } & \multicolumn{3}{|c|}{$\mathbf{2 0 0 0}$} & \multicolumn{2}{|c|}{$\mathbf{2 0 1 0}$} & \\
\cline { 2 - 7 } & \multicolumn{1}{|c|}{ A } & \multicolumn{1}{c|}{ B } & \multicolumn{1}{c|}{ Total } & \multicolumn{1}{c|}{ A } & \multicolumn{1}{c|}{ B } & Total \\
\hline Ambulantes e Biscateiros & 98,0 & 2,0 & 100 & 97,5 & 2,5 & 100 \\
TRABALHADORES AGRícOLAS & $\mathbf{9 9 , 3}$ & $\mathbf{0 , 7}$ & $\mathbf{1 0 0}$ & $\mathbf{9 9 , 2}$ & $\mathbf{0 , 8}$ & $\mathbf{1 0 0}$ \\
Agricultores & 99,3 & 0,7 & 100 & 99,2 & 0,8 & 100 \\
Total & 94,8 & 5,2 & 100 & 89 & 11 & 100 \\
\hline
\end{tabular}

Nota:

$$
\begin{gathered}
\text { A = 0cupados residentes na mesorregião Norte } \\
\text { B }=\text { Ocupados que se deslocam para a mesorregião Norte } \\
\text { Fonte: IBGE, Censo Demográfico } 2000 \text { e 2010. Elaboração própria a partir das } \\
\text { categorias sócio-ocupacionais do Observatório das Metrópoles, } 2017 .
\end{gathered}
$$

\section{Região Sul Fluminense}

Na mesorregião Sul Fluminense, o principal tipo de deslocamento da população observado entre os municípios é aquele que ocorre dentro da própria mesorregião. Entretanto, é interessante se atentar que houve uma mudança de 4.567 para 9.495 pessoas que se deslocavam da RMRJ, representando um aumento de $108 \%$. Nos deslocamentos a partir de outros municípios do ERJ e do Brasil, nota-se um aumento de 67,1\%, nos quais o número de indivíduos passou de 7.593 para 12.685. O fato de tanto os ocupados de municípios da RMRJ quanto os de outros municípios terem variado positivamente em termos absolutos, pouco representou na distribuição apresentada em 2010. Ao compararmos a distribuição dessa estrutura com a apresentada pelo Norte Fluminense (Tabela 4), fica evidente a diferença da segmentação espacial do trabalho nessas regiões. O Norte apresenta uma dinâmica de maior atração de mão de obra de outras regiões. Essa constatação decorre do fato de na mesorregião Norte somente $33 \%$ dos deslocamentos serem de residentes da própria região, enquanto no Sul esse tipo deslocamento correspondia a 76\%. O fato de maior deslocamento de mão de obra ser interno da própria região Sul pode decorrer tanto das características das indústrias que foram atraídas para seu território, quanto da presença histórica e já consolidada de atividades industriais nessa mesorregião. Mas também pode decorrer da existência de uma oferta de trabalho adequada às exigências das indústrias que aí se estabelecem em função de esse espaço já se caracterizar historicamente 
como sendo um espaço de produção industrial. Ou ainda, pode decorrer do fato de que os ramos industriais que se instalaram nos municípios dessa mesorregião requerem pouca mão de obra, por se tratar de estruturas produtivas de nível elevado de desenvolvimento tecnológico.

Tabela 6 - Município de origem das pessoas que realizam deslocamento para mesorregião Sul Fluminense para trabalho ou estudo - 2000 e 2010

\begin{tabular}{|c|c|c|c|c|c|c|c|c|}
\hline \multirow{5}{*}{ Município de origem } & \multicolumn{8}{|c|}{ Deslocamento para mesorregião Sul } \\
\hline & \multirow{3}{*}{\multicolumn{2}{|c|}{2000}} & \multicolumn{6}{|c|}{2010} \\
\hline & & & \multicolumn{4}{|c|}{ Motivo } & \multirow{2}{*}{\multicolumn{2}{|c|}{ Total }} \\
\hline & & & \multicolumn{2}{|c|}{ Trabalho } & \multicolumn{2}{|c|}{ Estudo } & & \\
\hline & N. & $\%$ & N. & $\%$ & $\mathrm{~N}$ & $\%$. & $\mathrm{N}$ & $\%$. \\
\hline Municípios da mesorregião Sul & 41.668 & 77,4 & 52.012 & 76,5 & 19.808 & 76,1 & 71.897 & 76,4 \\
\hline Municípios da RMRJ & 4.567 & 8,5 & 7.668 & 11,3 & 1.816 & 7,0 & 9.495 & 10,1 \\
\hline Outros municípios do ERJ e Brasil & 7.593 & 14,1 & 8.269 & 12,2 & 4.404 & 16,9 & 12.685 & 13,5 \\
\hline Total & 53.828 & 100 & 67.948 & 100 & 26.029 & 100 & 94.077 & 100 \\
\hline
\end{tabular}

Fonte: IBGE, Censo Demográfico 2000 e 2010. Elaboração própria, 2017.

A Tabela 7 expressa a participação dos ocupados residentes na mesorregião Sul Fluminense e dos ocupados que se deslocam para essa mesorregião para trabalho de acordo com as categorias sócio-ocupacionais tanto em 2000 quanto em 2010. As únicas categorias sócio-ocupacionais que tiveram aumento expressivo na participação da população ocupada que realizam deslocamentos no período de 2000 e 2010 foram os dirigentes do setor privado, que aumentaram sua participação de 5,1\% para $17,6 \%$, representando um aumento de 12,5 pontos percentuais, e os dirigentes do setor público, que aumentaram de $1,3 \%$ para $9 \%$ o percentual de pessoas que se descolocam para a mesorregião Sul, o correspondente a um aumento de 7,7 pontos percentuais. Todas as outras categorias ou tiveram um aumento pouco expressivo ou tiveram redução nessa participação, o que poderia ser visto pelo conjunto da população ocupada, pois em 2000 a participação da população ocupada que era atraída de fora da mesorregião Sul era de 2,6\%, em 2010 passou para 3,2, um aumento de apenas 0,6 pontos percentuais. Esses dados demonstram, portanto, que nessa mesorregião a dinâmica do mercado de trabalho é organizada a partir da mão de obra existente na própria mesorregião, pois proporcionalmente 
é muito pequena a quantidade de pessoas atraída de outras regiões pelo mercado de trabalho do Sul Fluminense.

Tabela 7 - Participação dos ocupados residentes na mesorregião Sul Fluminense e os ocupados que se deslocam para mesorregião Sul Fluminense para trabalho nas categorias sócioocupacionais -2000 e 2010

\begin{tabular}{|c|c|c|c|c|c|c|}
\hline \multirow{2}{*}{ CATEGORIAS SÓCIO-OCUPACIONAIS } & \multicolumn{3}{|c|}{2000} & \multicolumn{2}{|c|}{2010} & \multirow[b]{2}{*}{ Total } \\
\hline & A & B & Total & A & B & \\
\hline DIRIGENTES & 97,5 & 2,5 & 100 & 93,1 & 6,9 & 100 \\
\hline Grandes Empregadores & 98,0 & 2,0 & 100 & 95,7 & 4,3 & 100 \\
\hline Dirigentes do Setor Público & 98,7 & 1,3 & 100 & 91,0 & 9,0 & 100 \\
\hline Dirigentes do Setor Privado & 94,9 & 5,1 & 100 & 82,4 & 17,6 & 100 \\
\hline PROFISSIONAIS DE NÍVEL SUPERIOR & 94,8 & 5,2 & 100 & 94,5 & 5,5 & 100 \\
\hline Profissionais Autônomos de Nível Superior & 97,7 & 2,3 & 100 & 97,7 & 2,3 & 100 \\
\hline Profissionais Empregados de Nível Superior & 92,8 & 7,2 & 100 & 94,1 & 5,9 & 100 \\
\hline Profissionais Estatutários de Nível Superior & 89,5 & 10,5 & 100 & 88,2 & 11,8 & 100 \\
\hline Professores de Nível Superior & 96,4 & 3,6 & 100 & 94,6 & 5,4 & 100 \\
\hline PEQUENOS EMPREGADORES & 97,3 & 2,7 & 100 & 98,9 & 1,1 & 100 \\
\hline Pequenos Empregadores & 97,3 & 2,7 & 100 & 98,9 & 1,1 & 100 \\
\hline OCUPAÇÕES MÉDIAS & 95,9 & 4,1 & 100 & 95,9 & 4,1 & 100 \\
\hline Ocupações Artísticas e Similares & 97,7 & 2,3 & 100 & 95,6 & 4,4 & 100 \\
\hline Ocupações de Escritório & 98,4 & 1,6 & 100 & 97,9 & 2,1 & 100 \\
\hline Ocupações de Supervisão & 96,6 & 3,4 & 100 & 95,3 & 4,7 & 100 \\
\hline Ocupações Técnicas & 95,2 & 4,8 & 100 & 95,5 & 4,5 & 100 \\
\hline Ocupações Médias da Saúde e Educação & 98,0 & 2,0 & 100 & 97,0 & 3,0 & 100 \\
\hline $\begin{array}{l}\text { Ocupações de Segurança Pública, Justiça } \\
\text { e Correios }\end{array}$ & 81,6 & 18,4 & 100 & 84,3 & 15,7 & 100 \\
\hline $\begin{array}{l}\text { TRABALHADORES DO TERCIÁRIO } \\
\text { ESPECIALIZADO }\end{array}$ & 98,8 & 1,2 & 100 & 98,4 & 1,6 & 100 \\
\hline Trabalhadores do Comércio & 98,7 & 1,3 & 100 & 98,7 & 1,3 & 100 \\
\hline Prestadores de Serviços Especializados & 98,8 & 1,2 & 100 & 98,1 & 1,9 & 100 \\
\hline
\end{tabular}




\section{政:}

$E m \%$

\begin{tabular}{|c|c|c|c|c|c|c|}
\hline \multirow{2}{*}{ CATEGORIAS SÓCIO-OCUPACIONAIS } & \multicolumn{3}{|c|}{2000} & \multicolumn{2}{|c|}{2010} & \multirow[b]{2}{*}{ Total } \\
\hline & A & B & Total & A & B & \\
\hline TRABALHADORES DO SECUNDÁRIO & 97,2 & 2,8 & 100 & 95,9 & 4,1 & 100 \\
\hline Trabalhadores da Indústria Moderna & 96,8 & 3,2 & 100 & 95,1 & 4,9 & 100 \\
\hline Trabalhadores da Indústria Tradicional & 98,8 & 1,2 & 100 & 97,1 & 2,9 & 100 \\
\hline Operários dos Serviços Auxiliares & 96,7 & 3,3 & 100 & 96,1 & 3,9 & 100 \\
\hline Operários da Construção Civil & 97,3 & 2,7 & 100 & 96,2 & 3,8 & 100 \\
\hline $\begin{array}{l}\text { TRABALHADORES DO TERCIÁRIO NÃO } \\
\text { ESPECIALIZADO }\end{array}$ & 99,0 & 1,0 & 100 & 98,6 & 1,4 & 100 \\
\hline Prestadores de Serviços Não Especializados & 98,8 & 1,2 & 100 & 98,2 & 1,8 & 100 \\
\hline Trabalhadores Domésticos & 99,3 & 0,7 & 100 & 98,8 & 1,2 & 100 \\
\hline Ambulantes e Biscateiros & 98,3 & 1,7 & 100 & 98,6 & 1,4 & 100 \\
\hline TRABALHADORES AGRÍCOLAS & 98,4 & 1,6 & 100 & 97,9 & 2,1 & 100 \\
\hline Agricultores & 98,4 & 1,6 & 100 & 97,9 & 2,1 & 100 \\
\hline Total & 97,4 & 2,6 & 100 & 96,8 & 3,2 & 100 \\
\hline $\begin{array}{r}\text { A = 0cupa } \\
\mathrm{B}=\text { Ocupados } \\
\text { Fonte: IBGE, Censo Demo } \\
\text { categorias sócio-ocup }\end{array}$ & $\begin{array}{l}\text { de } \\
02 \\
\text { lais }\end{array}$ & $\begin{array}{l}n \text { pa } \\
201\end{array}$ & $\begin{array}{l}\text { rregiã } \\
\text { mesor } \\
\text { aboraç } \\
\text { o das }\end{array}$ & $\begin{array}{l}\text { te } \\
\text { Nor } \\
\text { pria } \\
\text { poles }\end{array}$ & $\begin{array}{l}\text { ir das } \\
7 .\end{array}$ & \\
\hline
\end{tabular}

Considerações finais

Este trabalho buscou analisar a divisão socioespacial do trabalho e a segmentação espacial do mercado de trabalho no Estado do Rio de Janeiro entre os anos de 2000 e 2010. O recorte temporal se deu como estratégia de pesquisa tendo em vista a maior a rodada de investimentos indústrias ocorridas no Estado do Rio de Janeiro, colocando-se como comportamento contrário daquilo que se observava em décadas anteriores. A hipótese que se levantou foi que ocorreu mudanças importantes na divisão socioespacial do trabalho com reflexos na segmentação espacial do mercado de trabalho, apesar de não terem sido tão significativas.

A partir da análise dos indicadores econômicos, o quadro que se apresentou foi uma relativa mudança na divisão socioespacial do trabalho no Estado do Rio de Janeiro. A referida mudança se fundamentou em dois pilares: a perda de participação da Região Metropolitana do Rio de Janeiro no VAB industrial e de serviços, e o aumento de participação 
do Norte e Sul Fluminenses no VAB industrial e de serviços. Notou-se que o Norte, em especial, apresentou mudança expressiva, guinada pela demanda internacional de petróleo.

Paralelamente, a conjuntura supracitada trouxe reflexos diretos em indicadores do mercado de trabalho. Entretanto, de modo geral, houve manutenção da estrutura sócio-ocupacional do ERJ e das mesorregiões analisadas, com relativa centralidade da RMRJ, apesar de se destacar aumento de participação na categoria dos trabalhadores do secundário tanto na mesorregião Norte quanto na Sul, impulsionadas pelo aumento da participação dos trabalhadores da indústria moderna e dos operários dos serviços auxiliares.

Ao analisar o deslocamento casa-trabalho foi possível entender as particularidades e distinções entre as mesorregiões Norte e Sul. Em geral, houve aumento de participação no deslocamento dos ocupados de outras regiões para o Norte Fluminense, principalmente de pessoas ocupadas ligadas tanto ao setor público quanto às atividades produtivas, o que demonstram que os investimentos ocorridos nessa mesorregião requereram atração de mão de obra de outras regiões. O mesmo não se verificou na região Sul Fluminense, pois o aumento no deslocamento de pessoas para essa região foi muito pequeno. Isso significa que os investimentos nela realizados não requereu atração de mão de obra de outras regiões.

Essas evidências podem ser compreendidas em razão da característica da estrutura produtiva e do mercado de trabalho de cada mesorregião. No Norte Fluminense que somente a partir dos anos 1990 passou a realizar de modo sistemático a exploração da indústria extrativista, não havia nesse espaço a mão de obra adequada, qualitativa e quantitativamente, para realizar suas exigências, por este motivo foi necessário atrair mão de obra de outras regiões do estado e do país. No Sul Fluminense, a instalação de novas plantas industriais não requereu do mesmo modo a atração de mão de obra de fora por dois motivos aparentemente divergentes, mas que podem ser complementares: (i) porque aí já havia se constituído no passado um espaço de produção industrial, o que possibilitou o atendimento da demanda por certas mão de obras especializadas; (ii) porque o padrão tecnológico das novas plantas industriais que aí passaram a se localizar tem como característica a demanda por pouca mão de obra. Ou seja, as condições pretéritas da estrutura econômica e do mercado de trabalho 
e o novo padrão tecnológico industrial influenciam no modo como se operam as mudanças na segmentação espacial do mercado de trabalho. Isso também é válido para a RMRJ, pois continuou assegurando uma estrutura sócio-ocupacional semelhante entre os anos 2000 e 2010, decorrente do grande peso que a sua estrutura produtiva já apresentava na economia do ERJ, mesmo tendo sofrido mudanças na sua participação relativa nos setores industriais e de serviços.

\section{Notas}

1 A Mesorregião Metropolitana corresponde à classificação feita pelo IBGE, enquanto a Região Metropolitana é a região, com menos municípios, instituída por lei complementar estadual. Para facilitar a análise, se dividiu a Mesorregião Metropolitana do IBGE entre RMRJ e Perimetropolitana, sendo a primeira aquela instituída pelo Estado e a segunda, os municípios restantes que completam a classificação do IBGE.

2 São eles: (i) dirigentes, (ii) profissionais de nível superior, (iii) pequenos empregadores, (iv) ocupações médias, (v) trabalhadores do terciário especializado, (vi) trabalhadores do secundário, (vii) trabalhadores do terciário não-especializado e (viii) trabalhadores agrícolas.

\section{Referências}

ARBIX, G.; RODRÍGUES-POSE, A. Estratégias do desperdício: a guerra fiscal e as incertezas do desenvolvimento. Novos Estudos CEBRAP, São Paulo, v. 2, n. 54, p. 55-71, 1999. Disponível em: <http://novosestudos.uol.com.br/produto/ edicao-54/>. Acesso em: 15 de março de 2017.

BALTAR, P. E. A. Estagnação da economia, abertura e crise de emprego urbano no Brasil. Economia e Sociedade, Campinas, v. 6, p. 75-112, 1996. Disponível em: $<$ http://www.eco.unicamp.br/docprod/downarq.php?id=441\&tp=a $>$. Acesso em: 11 de fevereiro de 2017.

IBGE. Instituto Brasileiro de Geografia e Estatística. Panorama nacional e internacional da produção de indicadores sociais. Organizado por André Simões e Betina Fresneda. organizadores. Rio de Janeiro: IBGE, Coordenação de População e Indicadores Sociais, 2016.

HASENCLEVER, L. et al. Desempenho econômico do Rio de Janeiro: trajetórias passadas e perspectivas futuras. Dados, Rio de Janeiro, v. 55, n.3, p. 681-711, 2012.

MATTOS, F. A. M. de; LIMA, S. da S. Apontamentos para o debate sobre o pleno emprego no Brasil. Economia e sociedade, Campinas, v. 24, n. 2, 2015. Disponível em < http://www.scielo.br/scielo.php?script=sci arttext\&pid=S010406182015000200293\&lng=pt\&nrm=iso >. Acesso em: 15 de fevereiro de 2017. 
OLIVEIRA, A. de. A influência do território no comportamento do mercado de trabalho: notas sobre a experiência brasileira. Revista de Estudios Urbano Regionales (EURE), v. 43, n. 128, p. 81-98, 2017. Disponível em: <http://www. eure.cl/index.php/eure/article/view/1585/956>. Acesso em: 20 de fevereiro de 2018.

OSORIO, M.; REGO, H. R. S.; VERSIANI, M. H. Rio de Janeiro: reflexões e práticas. Rio de Janeiro: fatos e versões. Belo Horizonte: Fórum, 2016.

RIBEIRO, L. C. Q.; RIBEIRO, M. G.; COSTA, L. Estrutura Social no Brasil Metropolitano. In: RIBEIRO, M. G.; COSTA, L. G.; RIBEIRO, L. C. Q. (Org.). Estrutura social das metrópoles brasileiras: análise da primeira década do século XXI. 1. ed. Rio de Janeiro: Letra Capital, 2013.

SIQUEIRA, H. Estrutura produtiva e divisão espacial do trabalho no Estado e na metrópole. In: RIBEIRO, L. C. Q. (Org). Rio de Janeiro: transformações na ordem urbana. 1. ed. Rio de Janeiro: Letra Capital; Observatório das Metrópoles, 2015, p. 79-116.

Novo desenvolvimentismo e dinâmica urbano-regional no Brasil (2004-2012). Revista de Estudios Urbano Regionales (EURE), v. 41, n. 122, p. 261-277, 2015. Disponível em: <http://www.eure.cl/index.php/eure/article/ view/516/761>. Acesso em: 20 de junho de 2017.

SILVA, R. D. Indústria e Desenvolvimento no Rio de Janeiro: Um Olhar sobre a Baixada Fluminense e o Médio Paraíba. In: RAMALHO, R. J.; FORTES, A. (Org.). Desenvolvimento, Trabalho e Cidadania: Baixada e Sul Fluminense. 1. ed. Rio de Janeiro: Editora 7 Letras, 2012. p. 109-124. (v. 1).

Marcelo Gomes Ribeiro - Possui graduação em economia pela Pontifícia Universidade Católica de Goiás. É Mestre em Sociologia pela Universidade Federal de Goiás. Doutor em Planejamento Urbano e Regional. Professor do Instituto de Pesquisa e Planejamento Urbano e Regional da Universidade Federal do Rio de Janeiro. Possui Pós-Doutorado pela Universidade Federal do Rio de Janeiro. Atualmente é pesquisador do Observatório das Metrópoles. iD https://orcid.org/0000-0001-7448-0690.

Vitor Vilar Drumond - Graduando em Gestão Pública para o Desenvolvimento Econômico e Social do Instituto de Pesquisa e Planejamento Urbano e Regional da Universidade Federal do Rio de Janeiro.

(iD https://orcid.org/0000-0002-9762-608X.

\section{Contribuições dos autores}

Todos os autores ofereceram substanciais contribuições científicas e intelectuais ao estudo. O autor Marcelo Gomes Ribeiro foi o idealizador do projeto de pesquisa que resultou neste artigo. Suas contribuições se deram na elaboração teórico-conceitual do objeto de análise e revisão do 
manuscrito. O autor Vitor Vilar Drumond ficou responsável pela revisão bibliográfica e redação do texto. A extração dos dados, sua organização e interpretação foram feitas pelos dois autores. O texto final expressa um trabalho coletivo realizado ao longo de 2 anos de convivência e discussão entre os autores.

Recebido para publicação em 6 de outubro de 2018 Aceito para publicação em 17 de novembro de 2019 Publicado em 07 de março de 2019 